\title{
Corrosion Inhibition of 304 Stainless Steel using Neem Leaves Extract in Sulphuric Acid Solution
}

Dr. Abhay Singh

Associate Professor, Department of Chemistry, K.L.P. College, Rewari, India.Email: abhay1968.as@gmail.com

Copyright: () 2022 Dr. Abhay Singh. This is an open access article distributed under the terms of the Creative Commons Attribution License, which permits unrestricted use, distribution, and reproduction in any medium, provided the original author and source are credited.

Inhibition action of Neem leaves (Azadirachta Indica) extract on the corrosion of 304 stainless steel in 1.0M sulphuric acid solution has been investigated. The investigations were carried out using weight loss method and Scanning Election Microscopy (SEM) analysis. The results showed that the corrosion inhibition efficiency increases with increase in concentration of Neem leaves extract while it decreases with increase of temperature. SEM images indicated that the metal surface was in a better condition in the presence of inhibitor than the specimen exposed in the absence of the inhibitor. Results confirmed that Neem leaves extract acts as an efficient green corrosion inhibitor for 304 stainless steel in $1.0 \mathrm{M}$ sulphuric acid solution.

Keywords: Corrosion, Neem leaves, 304 stainless steel, Inhibitor, SEM.

\section{Introduction}

304 stainless steel is covered with a highly protective film of chromium oxyhydroxide $[1,2]$ and is resistant to corrosion in many aggressive environments. However, it suffers from uniform as well as pitting corrosion under certain acidic conditions. As 304 stainless steel has many applications in acidic medium in a variety of industries therefore protection of 304 stainless steel from corrosion in acidic medium is of great interest.

The use of corrosion inhibitors has been found to be the most effective and practical way of preventing metal corrosion [3,4]. However, the use of synthetic corrosion inhibitors suffers a major disadvantage of higher toxicity and as such their use has come under severe criticism. As such development of new corrosion inhibitors which effectively inhibit corrosion under a variety of conditions while being environmentally safe and acceptable is a challenging task [5].

Therefore, the plant extracts also known as Green Corrosion Inhibitors have become important because they are environmentally acceptable, inexpensive, readily available, renewable sources and eco-friendly [6]. Variety of plant extracts such as Carica Papaya and Camellia Sinensis [7], Euphoria Hirta [8], Vernomia Amygdalina [9,10] and many more have been studied for corrosion inhibition of metal and alloys in various media.

Neem tree is easily available all over India. Though, the use of Neem leaves extract as a corrosion inhibitor for mild steel in $\mathrm{HCl}$ and other media has been reported.

However, the use of Neem leaves extract for the corrosion inhibition of 304 stainless steel in sulphuric acid solution a very little is reported.

Thus the aim of the present study was to investigate the effect of Neem leaves extract on the corrosion of 304 stainless steel in 1.0M sulphuric acid solution, using weight loss method and the surface morphology of uninhibited and inhibited specimens have been studied using SEM. 


\section{Experimental Setup}

All the investigations were carried out using 304 stainless steel specimens which had the elemental composition as follows:

\begin{tabular}{|c|c|c|c|c|c|c|c|c|}
\hline Element & $\mathrm{C}$ & $\mathrm{Mn}$ & $\mathrm{S}$ & $\mathrm{P}$ & $\mathrm{Si}$ & $\mathrm{Ni}$ & $\mathrm{Cr}$ & $\mathrm{Fe}$ \\
\hline$\%(\mathrm{w} / \mathrm{w})$ & 0.045 & 1.47 & 0.008 & 0.06 & 0.37 & 7.98 & 17.04 & Balance \\
\hline
\end{tabular}

All the chemicals used were of AR grade and solutions were prepared using double distilled water.

\subsection{Preparation of Inhibitor}

Freshly collected Neem leaves were washed with tap water and then with double distilled water. Washed leaves were allowed to dry in the shadow for a few days.

The completely dried leaves were coarsely powdered and 50g was used for successive extraction in $250 \mathrm{ml}$ methanol for three days with periodic shaking. Then the extract was filtered and the filtrate was collected. The filtered liquid extract was evaporated to dryness and stored at room temperature in an air tight bottle and was used to prepare various. concentrations of the inhibitor

\subsection{Weight Loss Method}

Weight loss experiments were carried out using rectangular specimens of 304 stainless steel of size $2 \times 4 \mathrm{~cm}^{2}$ in the absence of inhibitor and in presence of 100, 200 and 400 ppm concentrations of Neem leaves extract in 1.0M sulphuric acid solution.

Experiments were performed at 20,30 and $40^{\circ} \mathrm{C}$ temperatures and the exposure time was 12 hours. The specimens in uninhibited and inhibited solutions were weighed using electronic balance before and after exposure to calculate the loss in weight due to corrosion.

\subsection{Surface Morphology Study}

To study the morphology of the corroded surface of the specimens, a Scanning Electron Microscope (Model JSM-840, JEOL Make) was used. The specimens were exposed to $1.0 \mathrm{M}$ sulphuric acid solution for 12 hours in the absence and presence of 200 and 400 ppm of Neem leaves extract as inhibitor.

\section{Results and Discussions}

The percentage inhibition efficiency results were calculated using the weight loss method for 304 stainless steel in presence of 100, 200 and $400 \mathrm{ppm}$ concentrations of Neem leaves extracted at 20,30 and $40^{\circ} \mathrm{C}$ temperatures are recorded in Table 1. The results in Table 1 indicated that Neem leaves extract acted as a good inhibitor to protect 304 stainless steel from corrosion in 1.0M sulphuric acid solution. A slight increase in inhibition efficiency was observed when the concentration of inhibitor was increased from 100 to 200 ppm. However, when the concentration of the inhibitor was increased from 200 to $400 \mathrm{ppm}$ the increase in the inhibition efficiency was quite noticeable. With the increase of temperature from 20 to $40^{\circ} \mathrm{C}$ the inhibition efficiency decreases gradually. A 
maximum inhibition efficiency of $88.9 \%$ was obtained using 400 ppm concentration of Neem leaves extract in $1.0 \mathrm{M}$ sulphuric acid solution at a temperature of $20^{\circ} \mathrm{C}$.

Table 1. Percentage Inhibition Efficiency of Neem Leaves Extract for corrosion of 304 Stainless Steel in 1.0 M sulphuric acid solution by weight loss method (Exposure Time $=12$ hours)

\begin{tabular}{|c|c|c|c|c|}
\hline $\begin{array}{c}\text { Concentration of } \\
\text { Inhibitor } \\
(\mathbf{p p m})\end{array}$ & $\begin{array}{c}\text { Temperature } \\
(\mathbf{0} \mathbf{C})\end{array}$ & $\begin{array}{c}\text { Weight Loss } \\
(\mathbf{m g})\end{array}$ & $\begin{array}{c}\text { Corrosion } \\
\text { Rate(mpy) }\end{array}$ & $\begin{array}{c}\text { Inhibition } \\
\text { Efficiency } \\
(\boldsymbol{\%})\end{array}$ \\
\hline \multirow{2}{*}{ Nil } & 20 & 79.50 & 359.77 & ---- \\
\cline { 2 - 5 } & 30 & 143.80 & 650.76 & ---- \\
\hline 100 & 40 & 194.52 & 880.29 & ---- \\
\hline 200 & 20 & 16.98 & 76.84 & 78.6 \\
\hline 400 & 20 & 15.13 & 68.47 & 80.9 \\
\hline 100 & 20 & 8.78 & 39.73 & 88.9 \\
\hline 200 & 30 & 56.34 & 254.96 & 60.8 \\
\hline 400 & 30 & 50.19 & 227.13 & 65.1 \\
\hline 100 & 30 & 26.13 & 118.25 & 81.8 \\
\hline 200 & 40 & 86.45 & 391.22 & 55.5 \\
\hline 400 & 40 & 80.38 & 363.75 & 58.6 \\
\hline & 40 & 46.52 & 210.52 & 76.0 \\
\hline
\end{tabular}

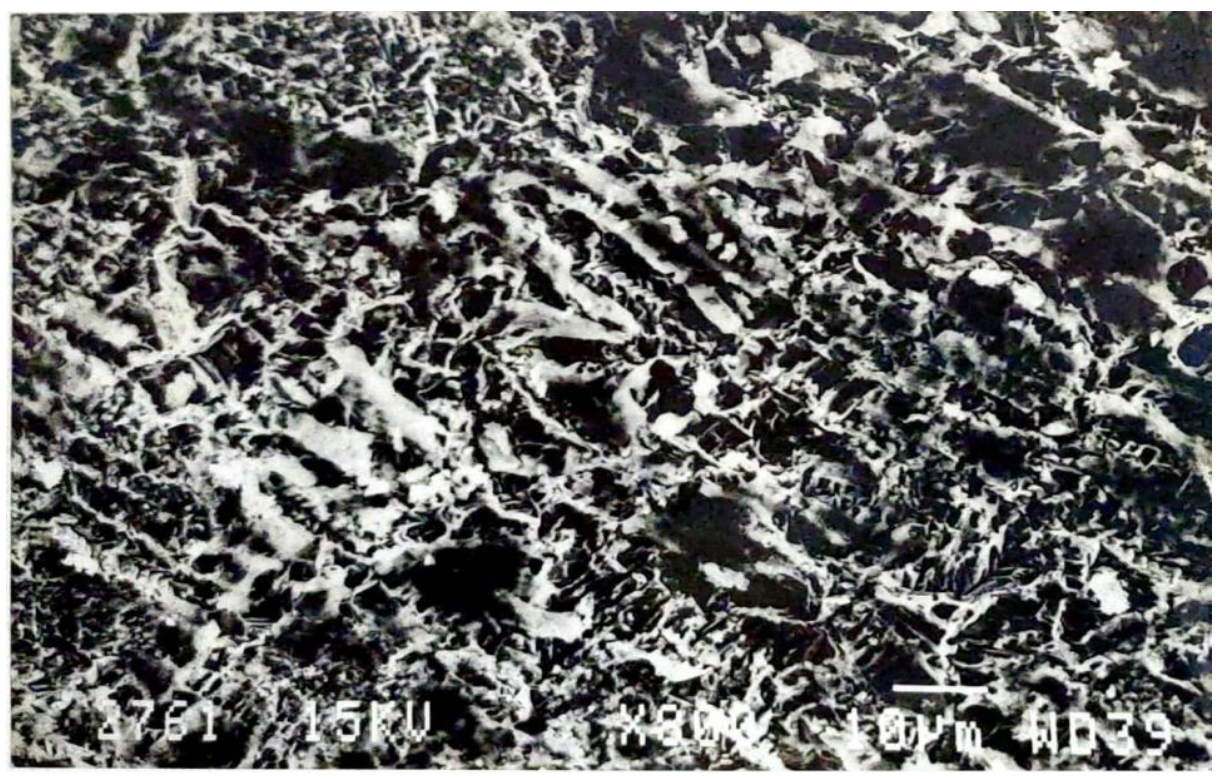

Fig.1(a) SEM micrograph of 304 stainless steel exposed to 1.0M sulphuric acid solution for 12 hours (x 800)

Fig.1(a) showed the scanning electron micrograph(SEM) of 304 stainless steel specimen exposed to $1.0 \mathrm{M}$ sulphuric acid solution for 12 hours and Fig. 1(b) and Fig.1(c) in presence of 200 ppm and 400ppm concentrations 
Asian Journal of Applied Science and Technology (AJAST) Volume 6, Issue 1, Pages 77-81, January-March 2022

of the inhibitor respectively. Fig. 1(a) indicated that 304 stainless steel surface was severely corroded in the absence of the inhibitor. However, the specimen surface was in better condition in 200ppm concentration of the inhibitor and the condition of surface further improved as the concentration of the inhibitor was further increased to 400ppm.

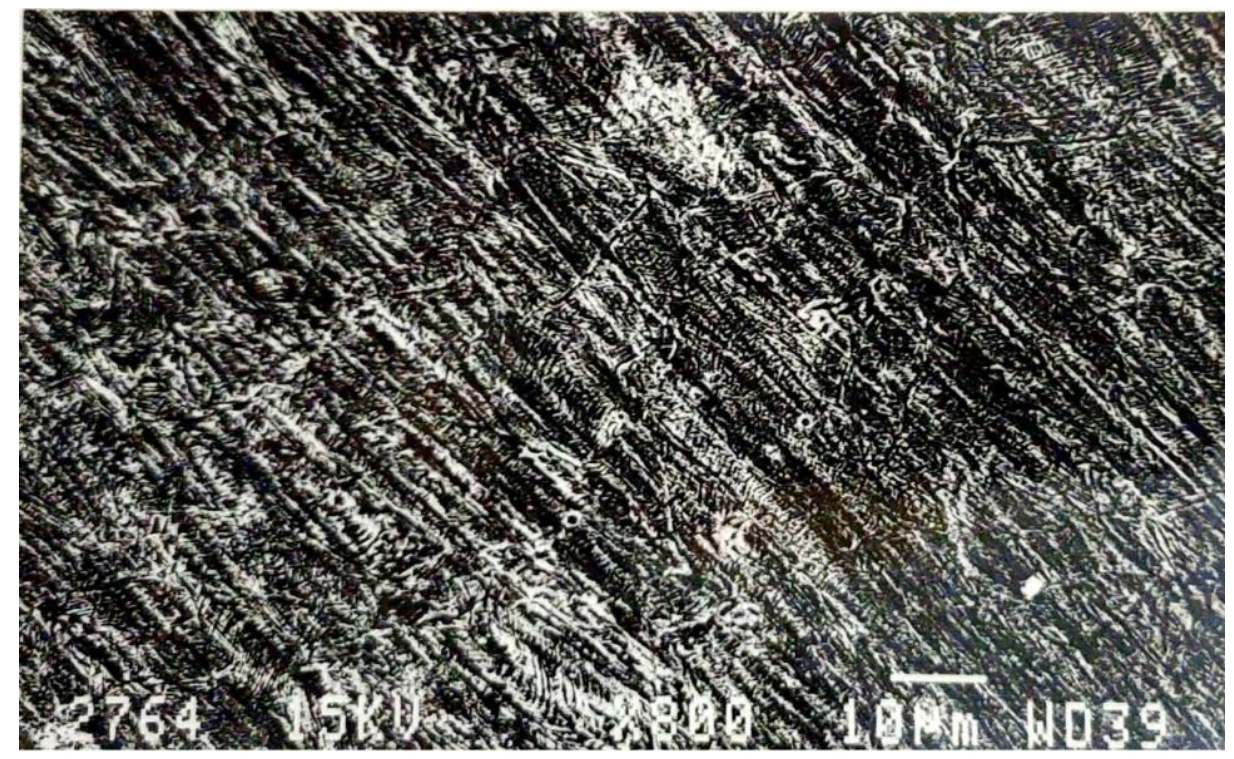

Fig.1(b) SEM micrograph of 304 stainless steel surface exposed to 1.0M sulphuric acid solution in presence of 200 ppm of Neem Leaves Extract for 12 hours (x 800)

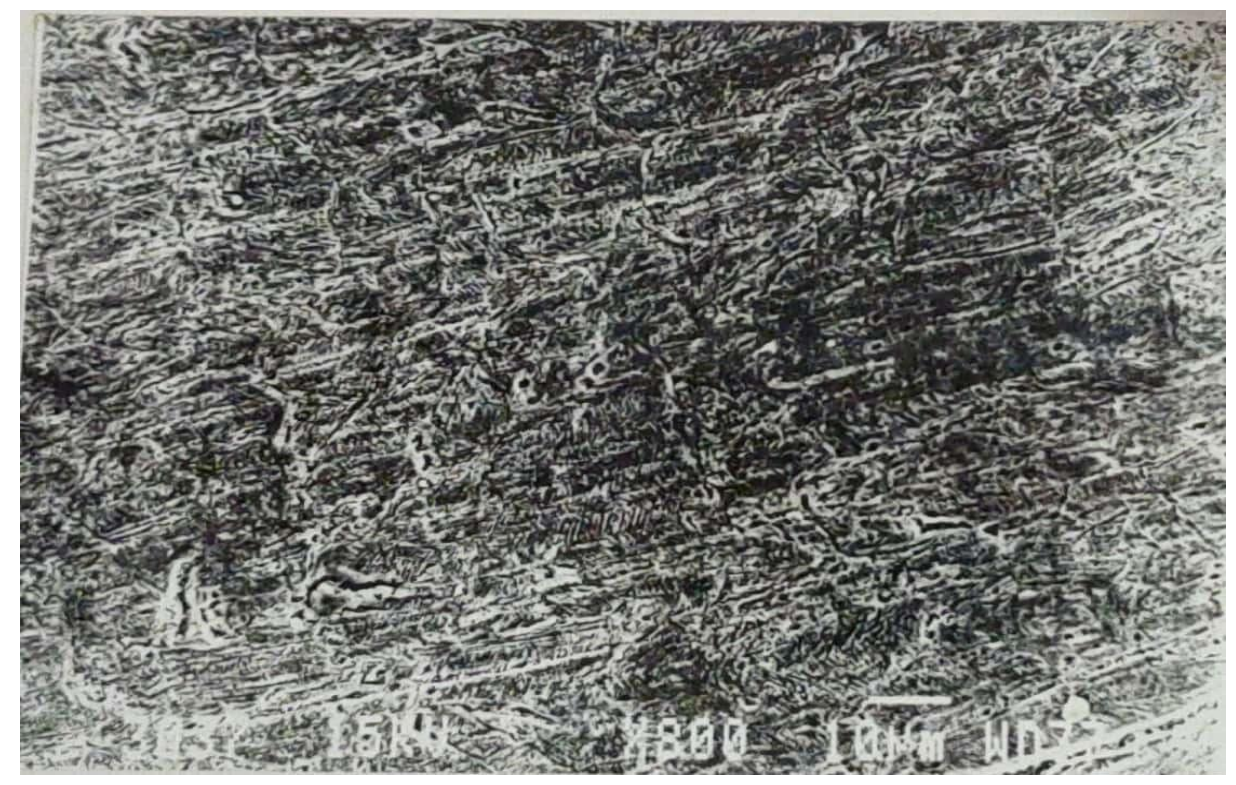

Fig.1(c) SEM micrograph of304 stainless steel surface exposed to 1.0M sulphuric acid solution in presence of 400 ppm of Neem Leaves Extract for 12 hours (x 800)

\section{Conclusions}

Neem leaves extract acted as a good green corrosion inhibitor for 304 stainless steel in 1.0M sulphuric and solution. The inhibition efficiency increases slightly when the concentration of inhibitor is increased from 100 to $200 \mathrm{ppm}$ but the increase in inhibition efficiency is appreciable when the concentration of inhibitor is increased to 400ppm. With the increase of temperature inhibition efficiency decreases. A maximum inhibition efficiency of $88.9 \%$ is 


\section{A IAST}

Asian Journal of Applied Science and Technology (AJAST)

Volume 6, Issue 1, Pages 77-81, January-March 2022

shown by inhibitor at $20^{\circ} \mathrm{C}$ and $400 \mathrm{ppm}$ concentration. SEM micrographs showed that inhibitor provided protection from corrosion by absorption on the surface of 304 stainless steel.

\section{Declarations}

\section{Source of Funding}

This research did not receive any specific grant from funding agencies in the public, commercial, or not-for-profit sectors.

\section{Competing Interests Statement}

The author declares no competing financial, professional and personal interests.

\section{Consent for publication}

Author declares that he/she consented for the publication of this research work.

\section{References}

[1] H. H. Uhlig and R.B. Mears in Corrosion Handbook, Ed. H.H. Uhlig, John Wiely \& Sons, New York (1948).

[2] G. Okamoto, Corrosion Science, 13 (1973) 471.

[3] B. Liu, H. Xi, Z. Li and Q. Xia, Appl. Surf. Sci., 258 (2012) 6679.

[4] A. Singh, A.K. Singh and M.A. Quraishi, Electrochem. J., 2 (2010) 189.

[5] R. Saratha and V. G. Vasudha, E-journal of Chemistry, Vol. 7(3)(2010) 677-684.

[6] M. Abde-Gaber, B. A. Abd-El-Nabay, I. M. Sidahmed, A. M. El-Zayady, M. Saadawy, Corr. Sci. Vol. 48, (2008) 2765-2779.

[7] Loto C.A. and Popoola A.P.I. Int. Electrochem. Sci., (2012), 7, 2983-2996.

[8] Nnanna A.L., Anozie I.U., Avoaja, Akoma C.S., Eti E.P. Afric. J. Pure Appl. Chem., 5(8), (2011) 265-271.

[9] Loto C.A., Joseph O.O, Loto R.T. and Popoola A.P.I. Int. J. Electrochem. Sci., 8, (2013)11087-11100.

[10] Loto C.A., Corr. Prev. Control., 50 (1), (2003) 43-49. 